\title{
Assessment of adverse drug reactions to antiretroviral agents among HIV patients
}

\author{
A. Pramod Kumar', S. Rajendra Prasad ${ }^{2}$, G. Parthasarathi ${ }^{1^{*}}$, U. Krishna ${ }^{1}$ \\ 'Dept. Pharmacy Practice, JSS College of Pharmacy, JSS University, Mysore, India. \\ ${ }^{2}$ Dept. General Medicine, JSS Medical College and Hospital, JSS University, Mysore, India.
}

\begin{tabular}{l}
\hline ARTICLE INFO \\
\hline Article history: \\
Received on: 19/07/2017 \\
Accepted on: 14/11/2017 \\
Available online: $27 / 02 / 2018$ \\
\hline Key words: \\
Antiretrovirals, HIV, ADRs.
\end{tabular}

\section{INTRODUCTION}

Human Immunodeficiency Virus (HIV) continues to be a major global public health issue. In 2016, an estimated 36.7 million people were living with HIV (including 1.8 million children) with a global HIV prevalence of $0.8 \%$ among adults. There were roughly 1.8 million new HIV infections occurred in 2016, a decline from 2.1 million new infections in 2015 (www.avert.org). India has the third largest HIV epidemic in the world with 2.1 million people living with HIV (PLHIV) in 2016. Children $(<15$ years) account for $6.54 \%$, while two fifth $(40.5 \%)$ of total HIV infections are among females. It was estimated that 1.3 million PLHIV in India needed ART in 2015 (www.NACO.org.in). The introduction of highly active antiretroviral therapy (HAART)

${ }^{*}$ Corresponding Author

G. Parthasarathi, Dean, Faculty of Pharmacy, JSS University, Mysore

-15, Karnataka, India.E-mail: gparthasarathi@jssuni.edu.in has led to a significant reduction in Acquired Immunodeficiency Syndrome (AIDS) related morbidity and mortality. In India, efforts of National AIDS Control Organization (NACO) to make available, the generic HAART, to HIV infected individuals, at no cost, has enormously increased the access to ARVs to the poor and needy (www.unaids.org).

The adverse effects of HAART are of serious concern as it may negatively affect the confidence in treatment resulting in decreased medication adherence (Srikanth et al., 2012). Hence, the safe and effective management of HIV infection also requires understanding of adverse drug reactions (ADRs) associated with HAART. Data obtained from the clinical trials regarding drug related adverse events in HIV positive patients has many limitations as this data includes selected and homogenous populations under well controlled conditions. On the other hand, most of the clinical trials including randomized studies evaluated only the efficacy of ARVs but were unable to detect rare and severe side effects. However, observational studies widely documented that ART 
induced ADRs has significant impact on the patients quality of life and adherence to ART (Rolfes et al., 2016; Rita et al., 2017).

There are limited numbers of studies conducted in India to intensively monitor the hospitalized HIV positive patients for possible ADRs and systematic documentation of the findings to analyze these ADRs. Hence, present study is designed to determine the prevalence, causality, predictability, preventability, and severity of ADRs among HIV patients admitted in two South Indian ART centers.

\section{MATERIALS AND METHODS}

This was a hospital based retrospective observational study conducted at two HIV care clinics in Mysore, Karnataka from July 2012-June 2015. All the spontaneous adverse drug reactions reported to fixed dose of HAART were included in the study. The study was approved by an institutional ethical committee of the study sites. Confidentiality of the information was assured in a way that no disclosure of any name of the patient or health care provider in relation to the finding was made. Patient and ADR related information was collected from the ADR reporting forms and patient case records. ADRs due to the medications used for treating the opportunistic infections and co-morbid conditions were excluded. Collected information on ADRs was reviewed by clinical pharmacists at the study site, further assessed in consultation with the study site treating physicians and was documented.

The preventability was determined by using modified criteria adopted from Schumock and Thornton. Any answer of "yes" to any question suggests that the ADR might have been preventable in having any allergy or previously documented similar type of reaction, inappropriate drug was chosen to patient condition or chosen dose, route and frequency of administration is in-appropriate to patient age or weight. Along with these it was also considered to be preventable if a toxic serum drug concentration was documented or any known treatment available for the occurred adverse drug reaction. ADRs are also considered to be probably preventable if any drug-drug interaction was cause for ADR, not performing the necessary lab tests, poor medication adherence is the cause for ADR or any possible preventive measures were not administered to the patient. Answering no to above all was considered to be non-preventable reaction (Schumock and Thornton, 1992).

Severity of a reaction was assessed by using Hartwig et al. scale and classified as mild, moderate and severe. ADRs are considered to be severe if patient outcomes fall in category permanent harm, lead to death and required any intensive medical care admission due to ADR. ADRs are considered to be moderate if withdrawal of suspected drug therapy was required, needing antidote, and lead to increase the hospital stay or reason for admission. Finally ADRs were classified to be mild if it doesn't require any change in the treatment or not requiring antidote (Hartwig et al., 1992). The predictability was determined by incidence rate obtained from the literature considered to be predictable if incidence rate is more than $1 \%$ and also on previous allergy history of ADRs. The causality assessment of all ADRs was performed by using WHO probability scale in identifying the causal relationship associated and were categorized accordingly among the six categories. Further, all the ADRs observed were grouped on the basis of system organ class on which they affected (Meyboom et al., 1997).

\section{RESULTS AND DISCUSSION}

A total of 1120 ADRs were reported in 860 patients (male 497, female 364). Majority (94.5\%) of reactions were predictable. Findings from this study in terms of predictability were similar to the study published earlier where $96.1 \%$ of the ADRs were reported as predictable (Modayil et al., 2010). Reactions such as pancreatitis, depression, Steven Johnson's Syndrome was not predictable and was less than $5 \%$ of total reports amongst the study population.

Among all the reactions, $331(29.5 \%)$ ADRs were "definitely preventable", 489 (43\%) were "probably preventable" while remaining $300(27.5 \%)$ were "not preventable" reactions. Hepatotoxicity was observed in study patients who were mainly on nevirapine based therapy. Liver enzyme levels (AST, ALT) were raised in these patients up to 2-3 folds from the normal value. Positive rechallenge was observed in our study patients to nevirapine and in many patients the drug was withdrawn and all patients recovered from the ADRs. Hepatitis was predictable and was seen with Non-nucleoside reverse transcriptase inhibitors (NNRTIs) class of drugs. However, while an ADR occurred, same class of drug was substituted due to limited access to second line regimen. Regular monitoring of liver enzymes in the patients initiated with NNRTIs might help in the early detection and prevention of occurrence of these reactions.

Gastrointestinal system disorders $19.75 \%$ (221) were observed in patients on zidovudine containing regimen after first few weeks of therapy and symptoms were self-limiting. The gastrointestinal system disorders were the reason for medication non-adherence in a study conducted by (Carr., and Cooper., 2000). However, they are preventable by educating the patients to take zidovudine with food and avoid the intake of zidovudine along with carbonated and caffeinated drinks.

Central and peripheral nervous system (CNS) disorders $10.62 \%(119 / 1120)$ like dizziness and peripheral neuropathy were observed in our study. Efavirenz and stavudine based regimens were mainly implicated in causing this CNS disorders. Peripheral neuropathy $5.8 \%$ (66) cases were observed in patients who were on stavudine containing regimen for more than six months. In all the cases, definite improvement was observed after discontinuation of stavudine. In addition to this dechallenge, pyridoxine was given to treat peripheral neuropathy in patients with severe condition. Majority of the patients complained of dizziness during night time. Dizziness may probably due to the administration of efavirenz at night. Symptoms were observed in the first two weeks of therapy and were self-limiting. A longitudinal study by (Fumaz et al., 2005) showed increased risk of experiencing CNS toxicity in the first two weeks of therapy. There was significant association between CNS toxicity and the efavirenz plasma levels. Administration of cinnarizine, an antihistamine along with efavirenz containing regimen may help in preventing/reducing severity of dizziness.

In our study anaemia $29.10 \%$ (326) was the most commonly observed ADR due to zidovudine + lamivudine + nevirapine/efavirenz regimen. This was probably a preventable reaction. Anaemia occurred (haemoglobin $<7 \mathrm{~g} / \mathrm{dl}$ ) within the first few months of initiation of therapy. In majority of the patients, 
improvement in haemoglobin level was observed once zidovudine containing regimen was withdrawn which was similar to the study conducted by (Kaibalya, et al.2015). So, the red blood cell disorders could have been minimized by regular monitoring of blood parameters. It is also advised not to start zidovudine in patients with haemoglobin less than $8 \mathrm{~g} / \mathrm{dl}$. However, implementation of such strategy may be difficult in a resource limited settings.

Some of the reactions like rash, urticaria of skin and appendages (10.62\%) and musculo-skeletal disorders like myalgia $(1.9 \%)$ were assessed to be not preventable. This probably indicates that good number of ADRs may occur even with implementation of some of the preventive measures.

Severity criteria assessment showed $390(34.8 \%)$ of the reactions were mild in nature whereas $659(58.8 \%)$ of the reactions were considered moderate and $71(6.4 \%)$ of the reactions were classified as severe in nature (Figure 1). Severe reactions were about $1 \%$ in our study population though no fatality was observed. About $34 \%$ of ADRs were reason for both hospitalization and for prolongation of hospitalization. Severe reactions found in our study were lactic acidosis, lipodystrophy and nail discoloration. The severity assessment carried out showed that $35 \%$ of the reactions was mild and in almost all these patients complete recovery was observed requiring no changes in the regimen. Very few ADRs were severe enough to necessitate the switchover to other regimen. Nevirapine induced Steven Johnson Syndrome was observed in patients receiving the Zidovudine + Lamivudine + Nevirapine regimen. These patients were hospitalized, dechallenged and substituted with other NNRTIs. Stavudine induced lipodystrophy also necessitated substitution of non stavudine based regimen. Reactions which were moderate in nature were managed by symptomatic treatment alone without changing the regimens.

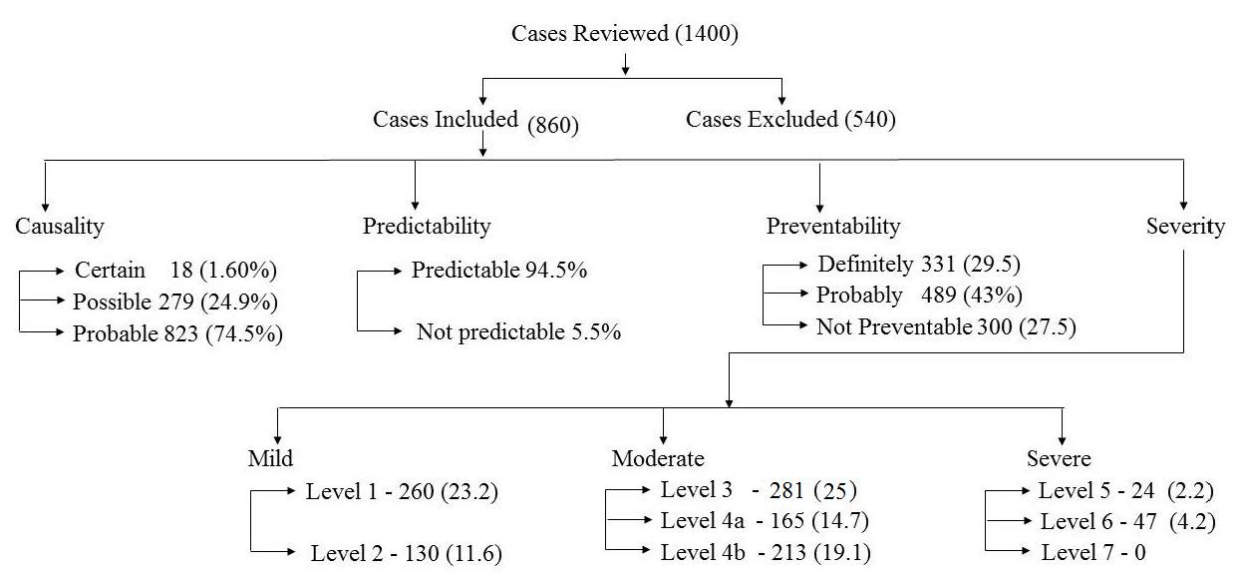

Fig. 1: Flow chart presentation of assessment of ADRs.

An epidemiological research conducted in India and Brazil on patients receiving ART revealed the occurrence of ADRs as 25.5\% and 34.5\%, respectively (Diwakar et al., 2012). A study by (Shet et al., 2014) clearly showed that adverse effects of various antiretrovirals were one of the major reasons for the treatment change.

The causality of the ADRs was evaluated and was found to be $823(74.5 \%)$ of reactions are probable whereas $279(24.90 \%)$ were possible and $18(1.60 \%)$ were definite in nature. IRIS $9.28 \%$ (104) was seen among study patients to ART regimens included both paradoxical and unmasking IRIS. In majority of the patients IRIS manifested as TB. IRIS presents challenges to the clinician in terms of diagnosis, management, decisions to continue ART, and, if ART need to be continued, motivating patients to adhere to the therapy despite symptom deterioration. These challenges are further compounded by the lack of both a diagnostic test and an evidence based guidelines for the management of IRIS. Similar findings were observed in a study from (Pramod et al., 2016).

Some reactions such as acute renal failure (ARF) 1.7\% observed to TDF based regimen, were probable in nature. So, TDF was substituted with other NRTI and reaction was reversible in majority of patients after cessation of the drugs. Among the patients who developed peripheral neuropathy, stavudine was withdrawn and a definite improvement was observed. This finding suggests that stavudine was attributed to the occurrence of peripheral neuropathy which is similar to study conducted and its establishment shown by (Reddy et al., n.d.). Stavudine was also found to cause majority of metabolic and nutritional disorders such as lipodystrophy in patients who received for more than two years which needed the substitution of this drug.

Table 1: Regimen implicated in ADRs.

\begin{tabular}{lc}
\hline Regimen & Number (\%) [n= 1120] \\
\hline Zidovudine + Lamivudine + Nevirapine & $586(52.32)$ \\
Zidovudine + Lamivudine + Efavirenz & $145(12.94)$ \\
Stavudine + Lamivudine + Nevirapine & $202(18.03)$ \\
Stavudine + Lamivudine + Efavirenz & $103(9.19)$ \\
Tenofovir + Lamivudine + Nevirapine & $38(3.39)$ \\
Tenofovir + Lamivudine + Efavirenz & $35(3.12)$ \\
Tenofovir + Lamivudine + Atazanavir/ritonavir & $07(0.62)$ \\
Stavudine + Lamivudine + Atazanavir/ritonavir & $04(0.35)$ \\
\hline
\end{tabular}

About $52.3 \%$ of reactions were attributed to zidovudine + lamivudine + nevirapine regimen followed by $18.2 \%$ due to stavudine + lamivudine + nevirapine regimen, others regimens implicated in ADRs are shown in Table 1. The system organ class which affected most was red blood cell disorder $29.10 \%$ followed by gastrointestinal disorder $19.73 \%$ and details pertaining to other system organ class are shown in Table 2. 
There were few limitations in our study. Firstly, as it is a retrospective study, we couldn't follow the patients for the prognosis of ADRs. Also because of irregular clinic attendance by patients, our study may underestimate the incidence of ADRs to ART. Secondly, limited access to laboratory facilities may also have contributed to under-recognition of ADRs those are identified based on lab reports.

Table 2: System organ class affected by reported ADR.

\begin{tabular}{|c|c|c|}
\hline $\begin{array}{l}\text { System Organ Class } \\
\text { (WHO ART SOC code) }\end{array}$ & Type of ADRs & $\begin{array}{l}\text { Number of ADRs }(\%) \\
{[n=1120]}\end{array}$ \\
\hline $\begin{array}{l}\text { Red blood cell disorder } \\
(1210)\end{array}$ & Anaemia (326) & $326(29.10)$ \\
\hline $\begin{array}{l}\text { Metabolic and nutritional } \\
\text { disorder }(0800)\end{array}$ & $\begin{array}{l}\text { Lactic Acidosis (58), } \\
\text { Lipodystrophy (25) }\end{array}$ & $83(7.41)$ \\
\hline $\begin{array}{l}\text { Central and peripheral } \\
\text { nervous system }(0410)\end{array}$ & $\begin{array}{c}\text { Headache (6), } \\
\text { Dizziness (47), } \\
\text { Peripheral Neuropathy (66) }\end{array}$ & $119(10.62)$ \\
\hline $\begin{array}{l}\text { Gastrointestinal system } \\
\text { disorders }(0600)\end{array}$ & $\begin{array}{c}\text { Vomiting (158), } \\
\text { Diarrhoea (18), } \\
\text { Gastritis (44), } \\
\text { Pancreatitis (01) }\end{array}$ & $221(19.73)$ \\
\hline $\begin{array}{l}\text { Liver and biliary system } \\
\text { disorder }(0700)\end{array}$ & $\begin{array}{l}\text { Hyperbilirubinemia (7), } \\
\text { Increased Liver Function } \\
\text { Tests }(50)\end{array}$ & $57(5.08)$ \\
\hline $\begin{array}{l}\text { Psychiatric Disorders } \\
(0500)\end{array}$ & $\begin{array}{l}\text { Insomnia (18), } \\
\text { Depression (6) }\end{array}$ & $24(2.14)$ \\
\hline $\begin{array}{l}\text { Skin and appendages } \\
\text { disorders }(0100)\end{array}$ & $\begin{array}{c}\text { Hyperpigmentation (04), } \\
\text { Rash (66), } \\
\text { SJS (10), } \\
\text { Itching (39) }\end{array}$ & $119(10.62)$ \\
\hline $\begin{array}{l}\text { Urinary system disorders } \\
(1300)\end{array}$ & $\begin{array}{l}\text { Acute Renal Failure (20), } \\
\text { Fancouni Syndrome (4) }\end{array}$ & $24(2.14)$ \\
\hline $\begin{array}{l}\text { White cell and RES disor- } \\
\text { ders }(1220)\end{array}$ & Leucopenia (13) & $13(1.21)$ \\
\hline $\begin{array}{l}\text { Body as a whole general } \\
\text { disorders }(1810)\end{array}$ & $\begin{array}{c}\text { Fatigue (5), } \\
\text { Hypersensitivity (3) }\end{array}$ & $08(0.71)$ \\
\hline $\begin{array}{l}\text { Resistance Mechanism } \\
\text { disorder (1830) }\end{array}$ & $\begin{array}{l}\text { Immune Reconstitution In- } \\
\text { flammatory Syndrome (104) }\end{array}$ & $104(9.28)$ \\
\hline $\begin{array}{l}\text { Musculo-Skeletal disorder } \\
(0200)\end{array}$ & Myalgia (22) & $22(1.96)$ \\
\hline
\end{tabular}

\section{CONCLUSION}

With the increasing access to use of HAART it is possible that there is an increased risk of drug induced illness due to HAART. As observed in this study many ADRs are predictable and possibly preventable. Early detection and management of ADRs will reduce the economic burden and improve the medication adherence resulting in better therapeutic outcomes.

\section{CONFLICTS OF INTEREST}

None to declare.

\section{FINANCIAL SUPPORT AND SPONSORSHIP}

$$
\text { Nil. }
$$

\section{REFERENCES}

Divakar B, Mistry SD, Kantharia ND, Mamtarani. The study of adverse drug reactions (ADR's) in HIV patients taking highly active antiretroviral therapy in ART centre, Surat, India. International journal of Medical and Pharmaceutical Sciences, 2012; 3(2):9-18.

Carr A, Cooper, DA. Adverse effects of antiretroviral therapy.
Lancet (London, England), 2000; 356:1423-30. doi:10.1016/S01406736(00)02854-3.

Fumaz CR, Muñoz-Moreno JA, Moltó J, Negredo E, Ferrer MJ, Sirera G et. al. Long-term neuropsychiatric disorders on efavirenz-based approaches: quality of life, psychologic issues and adherence. J Acquir Immune Defic Syndr, 2005; 38:560-5.

https://www.avert.org/global-hiv-and-aids-statistics.

Hartwig SC, Siegel J, Schneider PJ. Preventability and severity assessment in reporting adverse drug reactions. Am J Hosp Pharm, 1992; 49:2229-32.

Kaibalya Ranjan D, Lalit Kumar M, Hui P, Behera SK, Nayak, SN. High incidence of zidovudine induced anaemia in HIV infected patients in Southern Odisha. Indian J Hematol Blood Transfus, 2015; 31(2): 247-50. doi:10.1007/s12288-014- 0426-9.

Meyboom RH, Hekster YA, Egberts AC, Gribnau FW, Edwards IR. Causal or casual? The role of causality assessment in pharmacovigilance. Drug Saf, 1997; 17: 374-89.

Modayil RR, Harugeri A, Parthasarathi G, Ramesh M, Prasad $\mathrm{R}$, Naik $\mathrm{V}$ et. al. Adverse drug reactions to antiretroviral therapy (ART): an experience of spontaneous reporting and intensive monitoring from ART centre in India. Pharmacoepidemiol. Drug Saf, 2010; 19: 247-55. doi:10.1002/pds.1907.

Pramod Kumar A, Rajendra Prasad S, Parthasarathi G, Krishna U. Management of immune reconstitution inflammatory syndrome in HIV patients. International Journal of Universal Pharmacy and Biosciences, 2016; 5(3):303-11. upload/2015.

NACO [WWW Document], URL http://www.naco.gov.in/

Reddy AK, Lihite RJ, Lahkar M, Choudhury U, Baruah SK. A study on adverse drug reactions in HIV infected patients at a art centre of tertiary care hospital in guwahati, India. Asian J Pharm Clin Res, 2013; 6(2):102-04.

Rolfes L, van Hunsel F, Taxis K, van Puijenbroek E. The impact of experiencing adverse drug reactions on the patient's quality of life: A retrospective cross-sectional study in the Netherlands. Drug Saf, 2016; 39(8):769-76. doi:10.1007/s40264-016-0422-0.

Rita Kumari, Satish C, Manju G, Abha K. An assessment of adverse drug reaction patterns among HIV positive patients receiving antiretroviral therapy in a tertiary care hospital. International Journal of Pharmacological Research, 2017; 7(04):88-93.

Schumock GT, Thornton JP. Focusing on the preventability of adverse drug reactions. Hosp. Pharm, 1992; 27: 538.

Severe P, Jean Juste MA, Ambroise A, Eliacin L, March and C, Apollon S et al. Early versus standard antiretroviral therapy for HIVinfected adults in Haiti. N Engl J Med, 2010; 363:257-265. doi:10.1056/ NEJMoa0910370.

Shet A, Antony J, Arumugam K, Dodderi SK, Rodrigues R, DeCosta A. Influence of adverse drug reactions on treatment success: prospective cohort analysis of HIV-infected individuals initiating first-line antiretroviral therapy in India. PloS one, 2014; 10:9(3):e91028.

Srikanth BA, Babu SC, Yadav HN, Jain SK. Incidence of adverse drug reactions in human immuno deficiency virus-positive patients using highly active antiretroviral therapy. J Adv Pharm Technol Res, 2012; 3:62-7. doi:10.4103/2231-4040.93557.

WHO | www.who.int/hiv/en, 2016.

www.unaids.org/en/resources/fact-sheet.

\section{How to cite this article:}

Kumar AP, Prasad SR, Parthasarathi G, Krishna U. Assessment of adverse drug reactions to antiretroviral agents among HIV patients. J App Pharm Sci, 2018; 8(02): 079-082. 